\title{
Ciência, experimento e história em Bacon
}

\author{
Bacon on science, experiment and history
}

Plínio Junqueira Smith*

\begin{abstract}
Resumo: Este artigo visa a apresentar a concepção geral da grande restauração do conhecimento pretendida por Bacon. Para isso, apresentam-se, em primeiro lugar, os vários significados da palavra instauratio, mostrando como o projeto científico se reveste de um significado mais amplo, que inclui aspectos religiosos, políticos e históri$\cos$, e as seis partes que deveriam compor sua obra inacabada $A$ grande restauração. Em seguida, examinam-se sucessivamente os auxílios que Bacon propõe a cada uma das faculdades mentais: para o entendimento, um novo método ou via; para os sentidos, os experimentos; e, para a memória, uma nova história natural.
\end{abstract}

Palavras chave: ciência; experimento; história natural; método; indução; Bacon.

Abstract: The goal of this paper is to present Bacon's general view of the great restauration of knowledge. First, various meanings of the word instauratio are introduced, showing that it has also religious, political, and historical connotations, as well as the six parts that compose his unfinished work Instauratio Magna are presented. Next, it successively focuses on what Bacon proposes to aid each of the faculties of the human mind: to the understanding, a new method; to the senses, experiments; and to memory, a new kind of natural history.

Key words: Science; experiment; natural history; method; induction; Bacon.

\section{Introdução}

Um dos principais objetivos de Francis Bacon era a instauração de uma nova ciência, que substituísse as filosofias e as ciências herdadas dos gregos. ${ }^{1}$ Entre estas, o aristotelismo ocupa uma posição de destaque, pois é a filosofia reinante na época de Bacon, cuja concepção de ciência será questionada por Bacon. Além disso, é também tendo em vista a ciência emergente, na qual Galileu já se destacava, que Bacon buscará referências indispensáveis para teorizar sobre os procedimentos de uma nova ciência.

Pode-se dizer que a ordem do

\footnotetext{
${ }^{\star}$ Plínio Junqueira Smith é professor da Universidade Federal de São Paulo. E-mail:plinio.smith@gmail.com

${ }^{1}$ Eu gostaria de agradecer a Luiz Antonio Alves Eva e a Luciana Zaterka pelas inúmeras sugestões que me ajudaram a elaborar este texto, que deveria ter sido publicado como uma introdução geral ao pensamento de Bacon num livro que conteria a tradução da Instauratio Magna (e da Escala do intelecto) feita por Luiz Eva e Alessandro Rolim de Moura, e um artigo de Silvia Manzo. Infelizmente, o livro não foi publicado. A tradução foi publicada em Bacon (GR) e o artigo da Silvia saiu na revista Sképsis (Manzo 2015).
} 
conhecimento, em Bacon, começa com o experimento, prolonga-se com a história e culmina com a ciência. Cada etapa corresponde a uma faculdade da mente humana: ao experimento correspondem os sentidos; à história corresponde a memória; e à ciência corresponde o entendimento. Essa é a sequência natural da verdadeira indução, como ele a propõe: uma ascensão gradual e constante do experimento até às formas. ${ }^{2}$ Mas veremos, que, na prática, não ocorre um progresso lento e contínuo do conhecimento, como se este se afastasse progressivamente do experimento, dando-lhe permanentemente as costas. O recurso ao experimento é uma constante e algo necessário, do qual o homem de ciência nunca poderá abrir mão.

Para a melhor compreensão da instauração por ele pretendida, é mais adequado começar pela concepção de ciência e, depois, à luz dessa ideia, explicar sua concepção de experimento e de história. Antes, porém, cabe falar da obra de Bacon que deveria apresentar integralmente seu projeto, a Instauratio Magna. Assim, a exposição terá quatro partes: a primeira trata do sentido do termo "instauratio" e fornece uma ideia geral do projeto da Instauratio Magna; a segunda indica alguns aspectos da noção baconiana de ciência; a terceira mostra as consequências dessa concepção para a noção de experiência; a quarta, finalmente, expõe as consequências para a noção de história.

\section{A Instauratio magna.}

O título que Bacon escolhe para a sua principal obra é Instauratio Magna. O que significa essa "grande instauração"? Convém observar que nem sempre Bacon emprega instauratio, lançando mão de sinônimos. Por exemplo, no "Plano da obra" (p. 37), Bacon se refere a uma restauratio e, já no Novum Organum (I, 97), a uma regeneratio. Instauração, restauração, regeneração: Bacon parece usar essas três palavras indistintamente, sem atribuir-lhes nenhuma diferença significativa mais importante. Nos três casos, trata-se de indicar um novo caminho para o conhecimento científico do ho-

\footnotetext{
2É notória a dificuldade na interpretação do termo "forma” em Bacon. Ver, por exemplo, Pérez-Ramos (1999). Alguns viram mais um arcaísmo da linguagem de Bacon que, apesar de concepções modernas, manteve um vocabulário antiquado. O próprio Bacon confessa que ele conserva "os termos antigos, embora às vezes altere seus usos e definições" (PC II, VII, 2, p. 145/353). Outros viram uma antecipação da ideia de lei natural. Para uma interpretação da noção de forma associada à matéria, ver Zaterka (2012). Não é minha intenção entrar nesse debate, bastando-me indicar que a forma é o fim para o qual se dirige a ciência baconiana. Uma exposição sucinta da noção de forma encontra-se em PC II, VII, 5, p. 147-9/355-6.

${ }^{3}$ Manzo (2015) apresenta o projeto da Grande restauração por meio de uma análise de suas imagens.
} 
mem. A Instauratio Magna é, antes de tudo, a restauração da ciência (NO I, 38). ${ }^{3}$

Instauratio é uma palavra rica em significados. Primeiro, é inegável que Bacon atribuiu um sentido religioso preciso a essa palavra. Se ignorarmos essa referência, não entenderemos um aspecto importante de seu projeto filosófico e científico. ${ }^{4}$ É famoso o dito de Bacon, segundo o qual "um conhecimento pequeno ou superficial de filosofia pode inclinar a mente do homem ao ateísmo, mas um avanço subsequente a traz de volta para a religião" (PC I, I, 3, p. 24/267-8). Qual é, então, esse sentido religioso do termo?

A ideia de uma restauração é central, isto é, de algo que foi perdido e que deve ser por nós recuperado. Assim, a instauratio é a restauração do conhecimento que o homem tinha no estado prélapsário, antes do pecado original e da Queda, mas que pode ser, ao menos parcialmente, recuperado por uma ciência experimental adequadamente conduzida. "Pois o homem, pela Queda, caiu ao mesmo tempo de seu estado de inocência e de seu domínio sobre a cri- ação. Ambas as perdas, contudo, podem ser em parte remediadas ainda nesta vida; a primeira, pela religião e fé, a última pelas artes e ciências". ${ }^{5}$ Por exemplo, Adão e Eva não envelheciam, nem adoeciam no Paraíso. A ciência, portanto, deverá remediar esse efeito da Queda, ao menos em parte, adiando a morte e nos curando de doenças. Esse aspecto do pensamento de Bacon não passou despercebido entre seus comentadores. "Bacon sonhou, às vezes, reverter as consequências do pecado original e restaurar a humanidade por meio do poder da ciência à sua condição primitiva antes da Queda... Essa visão muito otimista da regeneração humana não combinava com a religião de sua época e com sua própria herança calvinista". ${ }^{6}$ Em suma, por meio de obras humanas, fruto da ciência, os homens poderiam restaurar parcialmente a condição anterior à Queda. ${ }^{7}$

O sentido com que Bacon emprega instauratio é, precisamente, o sentido que essa palavra tem na liturgia. A instauratio é a retomada de um rito religioso que foi interrompido por um erro. Quando, numa cerimônia, esta é interrom-

\footnotetext{
${ }^{4}$ Zagorin (1999, p. 49) faz o seguinte comentário: "Há alguns especialistas em Bacon que afirmam que Bacon era secretamente irreligioso, mas escondeu sua descrença. Seus escritos, contudo, não contém pistas ou enunciados para substanciar essa opinião".

${ }^{5}$ Works IV, 247-8. Ver, a esse respeito, PC I, I, 3, p. 20-5/264-8.

${ }^{6}$ Zagorin (1998), p. 45.

${ }^{7}$ Ver PC I, VI, p. 63-71/295-301.
} 
pida por um erro e deve ser reiniciada do ponto em que parou, então é preciso de uma instauratio do rito. Ora, é exatamente com esse sentido que Bacon usa instauratio: o pecado original e a Queda interromperam um conhecimento e um domínio que tínhamos sobre a criação e cabe, agora, retomá-los por meio de uma nova proposta operativa de ciência.

Um dos aspectos desse sentido religioso tem uma analogia com as reflexões de Bacon sobre as leis humanas, pois, em ambos os casos, se trata de propor regras para o conhecimento de leis. Bacon propôs uma reforma do direito e de como se conhecem as leis dos homens. A esse respeito, seria preciso uma investigação empírica com regras precisas. "A ciência da lei comum era uma descoberta progressiva de verdades práticas ocultas e envolvia suposições muito particulares sobre a natureza desse corpo de conhecimento e métodos altamente formais para fazer descobertas a partir dele". ${ }^{8}$ Assim como, no direito, uma ciência deve investigar para conhecer as leis humanas que regem o mundo humano, assim também, na natureza, uma ciência deve investigar para conhecer as leis divinas que regem o mundo natural. "As técnicas, bem como a terminologia do processo de Bacon para a descoberta das leis da natureza foram adaptadas dos processos legais ingleses". 9 O homem pode se aproximar das leis divinas por meio de seus efeitos, isto é, por uma investigação de sua obra.

A instauratio também tem um sentido político. Bacon sabia que, para efetuar essa restauração da ciência, seria preciso de uma reforma política. Mais precisamente, a restauração científica somente faria sentido num contexto político e social mais amplo. Como diz Martin, "a 'modernidade' de Bacon repousa na agenda e perspectiva (política) que deu nascimento e significado à nova forma de filosofia natural do Lorde Chanceler". ${ }^{10}$ Primeiro, a ciência não deveria mais ser praticada por homens isolados, mas por homens de ciência que trabalhassem conjuntamente e dotados de uma nova mentalidade. Estes deveriam ser formados e treinados especialmente para a investigação cooperativa da natureza. Nesse sentido, o projeto utópico baconiano de uma sociedade científica é bastante ilustrativo. ${ }^{11}$

Uma reforma das instituições, em particular das universidades, era indispensável aos olhos de Ba-

\footnotetext{
${ }^{8}$ Martin (1995), p. 80.

${ }^{9}$ Martin (1995), p. 85. Gaukroger (2001) retoma, com aprovação, essa interpretação de Martin.

${ }^{10}$ Martin (1995), p. 79.

${ }^{11}$ Ver Bacon (NA).
} 
con. Segundo Bacon, as instituições de ensino tinham um caráter, como diríamos hoje, "profissionalizantes", deixando pouco espaço para as artes e as ciências. Esse seria um erro grosseiro, pois "se alguém pensa que a filosofia e o conhecimento do universal são estudos ociosos, é alguém que não tem em conta que todas as profissões se servem e suprem deles" (PC II, I, 8, p. 105/324). Essa concepção de ensino é não somente prejudicial às ciências, mas também aos governos, que ficam desprovidos de quadros qualificados. Seria preciso, diz Bacon, melhorar o salários dos professores, "pois para o progresso das ciências é necessário que os professores sejam escolhidos entre os homens mais capazes e eficientes" (PC II, I, 9, p. 105/324). ${ }^{12}$

Finalmente, uma concepção tão ampla da nova ciência é muito cara e não poderia ser sustentada sem financiamento. "Em geral, dificilmente se fará avanço importante no desvelamento da natureza se não se designam fundos para gastos de experimentação, quer se trate de experimentos de Vulcano ou de Dédalo, de forno ou máquina, ou de qualquer outra espécie". (PC II, I, 7, p. 107/324). Ora, no entender de Bacon, caberia ao
Rei financiar a ciência e o conhecimento resultante deveria ser controlado pelo Rei em benefício de todos. O conhecimento produzido pelos homens de ciência não deveria permanecer no âmbito privado. "A novidade da filosofia natural de Bacon reside finalmente na sua insistência em que ela era uma atividade política de ordem elevada e um instrumento potente para promover a 'modernidade' que verdadeiramente dominou seus pensamentos e carreira: a construção mais sólida de um estado monárquico centralizado". ${ }^{13}$

Cabe destacar, finalmente, um sentido histórico da instauratio pretendida por Bacon. O aristotelismo, ou a ciência aristotélica, estava com os olhos voltados para o passado e buscava, nos livros antigos, a verdade sobre a natureza. No entanto, era preciso deixar de olhar para o passado e priorizar o futuro, abrindo uma nova possibilidade de conhecimento (NO, pref., parágrafo 4). Assim, a instauratio é uma ruptura, um marco na história da humanidade, o advento de uma nova era. Bacon estava consciente de seu lugar na história: a instauratio é um projeto histórico, isto é, Bacon pretende intervir na história humana, contribuindo para a determinação de novos rumos. Deve-

\footnotetext{
${ }^{12}$ Esse é, com efeito, a perspectiva com que Gaukroger (2001) interpreta a obra de Bacon.

${ }^{13}$ Martin (1995), p 87.
} 
se ver a filosofia de Bacon, menos como uma construção conceitual sofisticada e detalhada, do que como um empreendimento grandioso, que visa a promover uma mudança nos rumos da história civil dos homens.

Antes de analisarmos com mais cuidado as noções de ciência, experimento e história, é interessante dar ao leitor uma visão geral da Instauratio Magna. O próprio Bacon julgou que essa apresentação geral era indispensável, pois escreveu a Distributio opera, em que resumia o conteúdo de cada uma das seis partes que a Instauratio deveria conter. Essa é uma excelente introdução à obra de Bacon e permite delinear os aspectos centrais em torno dos quais toda a sua filosofia é construída. ${ }^{14}$

I. A primeira parte da Instauratio Magna dedica-se a uma avaliação do estado das ciências e a uma classificação geral das ciências. Um dos pontos fundamentais é mostrar que as ciências estão estagnadas há muito tempo. Esse é um forte indício de que há algo de podre no reino das ciências. Olhar para trás, esperando uma luz sobre a natureza, é um equívoco. É preciso olhar para o futuro e construir uma nova ciência. Uma das finalidades dessa nova ciência, no entender de Bacon, é melhorar a condição da existência humana e servir para o bem-estar da maioria, não somente conhecer a natureza. Essa parte incorpora, em grande medida, a obra anterior: $O$ progresso do conhecimento.

II. A segunda parte pretende fornecer instrumentos para a construção de uma nova ciência. Se a ciência aristotélica pretendia fornecer um organum para as ciências, Bacon pretenderá fornecer um novum organum: em vez dos silogismos, será preciso proceder de acordo com a verdadeira indução. A mente humana, longe de ser um meio neutro e indiferente aos conteúdos que recebe, vem ao mundo com uma série de tendências, inclinações e preconceitos que obstruem o conhecimento, além de, ao longo de nossas vidas, incorporar outros empecilhos ao conhecimento. Assim, será preciso administrar medidas que auxiliem a mente humana como um todo, fornecendo auxilio aos sentidos, à memória e ao intelecto ou entendimento. Essa é a parte da filosofia de Bacon mais bem desenvolvida e a que causou mais impacto na filosofia.

III. A terceira parte diz respeito à história e é nesta que começa o conhecimento propriamente dito. A nova ciência começa com o experimento e seu relato em histórias

\footnotetext{
${ }^{14}$ Para uma introdução à Grande Instauração, ver Morgado (2008).
} 
rigorosamente compiladas, ou seja, uma investigação exaustiva de todos os dados empíricos que se possam observar e coletar para de fato construir uma história experimental da natureza. Bacon divisa dois tipos de história: uma que é escrita para deleitar, outra que é escrita para servir de base para a ciência. A primeira é inútil para a ciência, somente relatando curiosidades, enquanto a última é a etapa indispensável pela qual deve começar a nova ciência. Desta última, há dois tipos: a história natural e a história civil. Bacon deixou alguns textos escritos nessa direção.

IV. A quarta parte consiste numa aplicação a um caso particular das regras fornecidas no livro II da parte II. Antes de começar a construção da ciência, é preciso ensaiar, por assim dizer, a prática científica. Como um aprendiz, algumas tentativas preliminares devem ser feitas antes de estar maduro para realizar a tarefa exigida pela ciência. É preciso mostrar como se pode passar, por meio das tábuas (de presença, ausência e comparação), aos axiomas e às formas.

V. A quinta parte apresenta alguns resultados positivos antes mesmo de se alcançar a ciência propriamente dita. Trata-se da "primeira colheita" ou "primeira vindima". Esta fornece os primeiros resultados do trabalho anterior e tem por finalidade assegurar que o procedimento aplicado traz bons frutos. Sendo o caminho em direção à ciência longo e árduo, poderse-ia desistir muito antes de se chegar à ciência. Para convencer de que se está no bom caminho, convém colher alguns resultados prévios como forma de incentivo. Mas não se deve pensar que Bacon reduz o interesse dessa parte aos seus aspectos psicológicos. Ao contrário, esses resultados são efetivamente produtos da ciência baconiana, tanto do ponto de vista do conhecimento, como do ponto de vista prático-operacional. Assim, essa parte seria como uma espécie de repouso no árduo caminho da ciência, recolhendo resultados parciais, provisórios e isolados, mas ainda assim suficientemente sólidos e úteis.

VI. A última parte é a construção da ciência propriamente dita. Bacon nada escreveu nessa parte e foi criticado por não ter feito nenhuma contribuição à ciência. Mas a crítica é injusta, já que, segundo a própria concepção de Bacon, a ciência é uma obra coletiva, caríssima e de longa duração. Não caberia a ele, Bacon, realizar a ciência, mas apenas indicar o caminho certo. Assim, há um caráter necessariamente incompleto e inacabado de sua obra. A parte VI só poderia ser elaborada por um grande número de homens de ci- 
ência, por muitos investimentos do Rei, ao longo de muito tempo e após muitos experimentos. Tanto é assim que a verdade é vista por Bacon, não mais como "a filha da autoridade", mas como "a filha do tempo". Portanto, nessa proposta filosófica Bacon ressalta o caráter provisório e hipotético da ciência, seu caráter progressivo, que será, sem sombra de dúvida, trilhado por muitos seguidores, por exemplo, da Royal Society, como Hooke, Boyle, Locke e Newton. ${ }^{15}$

\section{A ideia de ciência.}

Bacon elabora sua concepção de ciência a partir de uma oposição à maneira aristotélica de fazer ciência, que era então dominante. ${ }^{16}$ Segundo Bacon, "as ciências que possuímos nos foram legadas principalmente pelos gregos" (NO I, 71). ${ }^{17}$ Bacon tem em vista não toda a ciência grega, já que admirava os atomistas, como Demócrito, mas sobretudo a ciência aristotélica reinante em sua época. É, portanto, a partir dessa oposição que se deve delinear a concepção baconiana de ciência. Três, pelo menos, são os pontos em que a proposta baconiana de uma nova ciência se opõe à ciência aristotélica: 1) com relação ao fim com que se pratica a ciência; 2) com relação à natureza e à ordem das demonstrações; 3) com relação ao ponto de partida da ciência. Examinemos cada um deles com cuidado.

Qual o fim da ciência? Com que intenção se pratica a ciência? A ciência grega, no entender de Bacon, tem como finalidade precípua a invenção (1) de argumentos, (2) de coisas conformes aos princípios e (3) de razões prováveis (Distributio, p. 77). Nenhum desses parece constituir-se, de fato, num fim da ciência. Devemos examinar esses pontos com atenção, pois "o maior erro de todos é confundir ou situar indevidamente o fim último ou extremo do conhecimento" (PC I, V, 11 , p. 61/294).

Primeiro, haveria uma excessiva valorização dos argumentos, como se o essencial na atividade científica fosse criar novos argumentos a fim de refutar as teorias rivais. A esse respeito, a intenção da ciência grega seria somente vencer 0 adversário, como se a ciência fosse um campo de batalha e os homens de ciência lutassem pela vitória por meio de argumentos. Basta que

\footnotetext{
${ }^{15}$ Para as relações de Bacon com a Royal Society, ver Zaterka (2004).

${ }^{16}$ Nessa crítica ao aristotelismo, Bacon apropriou-se de maneira original do legado do ceticismo antigo e renascentista. A esse respeito, ver Eva (2008, 2011), Smith (2012) e Manzo (2017). O desenvolvimento da Teoria dos Ídolos pode ser visto em Rossi (2006, p. 145-206).

${ }^{17}$ No que se segue, usarei de maneira imprecisa a expressão "ciência grega", às vezes me limitando à ciência aristotélica, às vezes à filosofia grega de um modo mais geral.
} 
o adversário seja batido para que o homem de ciência considere ter logrado êxito. Reduzir o adversário ao silêncio, fazê-lo abandonar a teoria dele e convertê-lo à sua teoria, eis o que pretende um filósofo formado com o espírito da ciência grega. Não surpreende, assim, que a ciência antiga tenha algumas características que lhe são peculiares, como a discussão e polêmica. Ora, essas características essenciais da ciência grega são, aos olhos de Bacon, inimigas da busca da verdade (NO I, 20, 71). Sofistas e filósofos se organizaram em torno de seitas, com tom professoral, valorizando as disputas (NO I, 76). O que importava era triunfar na discussão. Uma vez destruídas as seitas adversárias, a autoridade passaria ao primeiro plano, já que a verdade estaria dada de uma vez por todas: os discípulos somente perpetuariam as doutrinas do mestre; o aristotelismo, em particular, se propagou dessa maneira através dos tempos (NO I, 77). A ciência seria, assim, uma realização individual, na qual um filósofo constrói de uma vez por todas um conjunto articulado de doutrinas sobre as coisas. Como as doutrinas se constroem sobre argumentos, a observação da natureza seria casual e secundária, com poucos experimentos sendo realizados e sem geração de frutos (NO I, 73). Esse eterno conflito das seitas, o res- peito à autoridade do mestre, a ausência de experimentos e observação levariam, inapelavelmente, à estagnação (NO I, 74).

Essa atitude se manteve na escolástica. "Sem dúvida alguma, assim como muitas substâncias são por natureza sólidas, apodrecem e se corrompem em vermes, do mesmo modo o conhecimento bom e correto tem a propriedade de apodrecer e dissolver-se em incontáveis questões sutis, ociosas, insanas e, por assim dizer, vermiculares, que têm de fato uma certa animação, mas nenhuma correção nem bondade. Esse tipo de saber degenerado prevaleceu sobretudo entre os escolásticos", que estariam encerrados nuns poucos autores, "principalmente Aristóteles, seu ditador" (PC I, IV, 5, p. 49/285). A sutileza dos escolásticos dizia respeito não somente ao assunto, mas especialmente ao método de tratar o conhecimento. $\mathrm{O}$ método empregado pelos escolásticos em suas infindáveis discussões era o de "sobre cada posição ou asserção particular compor objeções, e a essas objeções, soluções; soluções que em sua maior parte não eram contestações, mas distinções" (PC I, IV, 5, p. 50/286). Esse procedimento de traçar tantas distinções quantas fossem necessárias, entretanto, somente conduzia a uma discussão cada vez mais detalhada e inútil, sem jamais che- 
gar a qualquer conclusão. "E tal é seu método, que não se apóia tanto na evidência provada mediante argumentações, autoridades, similitudes, exemplos, como em contestações e soluções particulares para cada escrúpulo, cavilação e objeção, engendrando quase sempre uma dificuldade nova assim que se resolve outra" (PC I, IV, 5, p. 51/286). As disputas filosóficas perdiam-se, assim, em labirintos que não levavam a lugar nenhum.

Segundo, a ciência aristotélica começaria somente quando estivéssemos de posse de alguns princípios primeiros e, a partir deles, poderíamos deduzir coisas por meio do silogismo (mais adiante voltaremos a esse ponto). Assim, o estabelecimento de certas proposições que se seguiriam de maneira necessária seria um dos objetivos desse tipo de ciência. Não se deve construir a ciência a partir de supostos princípios primeiros, extraindo suas consequências, simplesmente porque esses princípios não são dados, nem são evidentes. Por isso, no entender de Bacon, devemos buscar os próprios princípios após longa e laboriosa investigação das coisas, partindo da experiência. De outro lado, a ideia de extrair dedutivamente coisas conformes aos princípios parece indicar que a coerência é um valor fundamental na elaboração de uma ci- ência. Para Bacon, a ciência certamente deve ser coerente, mas talvez a sobrevalorização da coerência possa ser um obstáculo ao progresso da ciência.

Terceiro, uma ciência propriamente dita não se contenta com argumentos meramente prováveis, mas busca estabelecer um conhecimento certo que nos indique como fazer coisas e controlar a natureza. Num contexto em que seitas rivais disputam a verdade por meio de argumentos e invocando o suposto conhecimento do fundador da seita, Bacon entende que esses argumentos não podem pretender nada além da verossimilhança. "Bem entendido, seu uso [do conhecimento que foi recolhido em outro tempo] não se limita a fornecer argumentos para disputar verossimilmente com outros, mas auxilia também nosso juízo para que nós mesmos cheguemos a conclusões corretas" (PC II, XIII, 9, p. 194/391). Ora, Bacon denuncia esse conformismo, que restringe a ciência à mera probabilidade, quando a ciência deveria almejar a certeza.

A ciência baconiana propõe-se fins muito diferentes: invenção das artes (e não de argumentos), dos próprios princípios (e não das coisas a partir dos princípios) e de obras (e não de razões prováveis). A finalidade prática da ciência é posta em relevo. Se a ciência pro- 
move o conhecimento, é porque Bacon não mais distingue entre conhecer e dominar a natureza. É famoso o aforismo: "Ciência e poder do homem coincidem, pois a ignorância da causa priva-nos do efeito. Não se triunfa sobre a natureza senão lhe obedecendo e o que na especulação vale como causa vale como regra na operação" (NO I, 3). A consequência imediata desses novos fins atribuídos à ciência é que, longe de pretender vencer os demais filósofos e homens de ciência, Bacon pretende vencer a natureza, isto é, pretende que a ciência seja capaz de operar sobre ela. Não se pode exagerar o caráter prático do conhecimento baconiano. ${ }^{18}$

Por isso, Bacon propõe um retorno às coisas mesmas, não ao discurso de autoridades sobre as coisas (NO I, 85). É preciso entender como as coisas estão articuladas no mundo, quais são as suas relações causais, para que se possam inventar um conhecimento certo e operar adequadamente sobre a natureza. Os demais filósofos e homens de ciência passam a ser vistos como colaboradores num mesmo empreendimento, e não como adversários teóricos. Assim, esses novos fins da ciência levam à concepção de um trabalho cooperativo e sistemático, que é produzido por todos conjuntamente. $\mathrm{O}$ conhecimento não pertence a este ou àquele filósofo, mas é de todos. O conhecimento científico adquire, assim, um caráter público, não estando restrito a pessoas em seu âmbito privado. Como vimos, esse conhecimento deve ser realizado de maneira institucional e financiado pelo Rei. Finalmente, Bacon entende que o progresso deve ser uma das marcas da nova ciência. A cooperação mútua dos homens de ciência, organizados em instituições adequadas para esses fins e apoiadas pelo Rei, deve promover o avanço do conhecimento científico e, portanto, do domínio sobre a natureza. O exemplo da Royal Society, uma sociedade de cientistas, de cunho empirista e que reconheciam em Bacon o seu patrono, é bastante ilustrativo.

Passemos ao segundo ponto. Qual a diferença na natureza e na ordem das demonstrações? Tratemos de cada parte dessa diferença em separado. No que diz respeito à natureza das demonstrações, a ciência aristotélica recorre predominantemente ao silogismo, enquanto a ciência baconiana apóia-se na indução. Veremos adiante o que Bacon entende exatamente por indução.

Aristóteles propôs o silogismo como um instrumento para o conhecimento. Fornecer ao entendi-

\footnotetext{
${ }^{18}$ Para o caráter técnico e operativo da ciência, ver Oliveira (2010).
} 
mento nas suas inferências regrar lógicas, identificando as formas lógicas válidas e distinguindo-as dos sofismas, seria o principal auxílio para a construção da ciência. Mas, no entender de Bacon, o silogismo é um remédio para o entendimento que chega tarde demais. O silogismo preserva a verdade das premissas, mas se as premissas não forem verdadeiras, o silogismo não é somente inútil, mas mesmo nocivo. "A lógica, tal como é hoje usada, mais vale para consolidar e perpetuar erros, fundados em noções vulgares, que para a indagação da verdade, de sorte que é mais danosa que útil" (NO I, 12). Ao menos dois são os problemas de recorrer somente à lógica e ao silogismo para auxiliar o intelecto.

Primeiro, uma vez que já se supôs (equivocadamente) que certos princípios gerais são verdadeiros e certas noções gerais correspondem às coisas, não adianta inferir validamente as conclusões. Se as premissas não são seguras, se não sabemos com certeza se os princípios gerais são verdadeiros, se os termos com que construímos nossos raciocínios são imprecisos, de que adianta que a forma lógica da inferência seja válida? O silogismo pressupõe princípios gerais, em vez de nos ajudar a descobrilos, e pode ser adequado para obter o assentimento do adversário, mas não o é para o conhecimento e do- mínio da natureza. "A lógica não se propõe inventar Ciências ou Axiomas das Ciências" (PC II, XIII, 2, p. 185/384). De fato, operando com axiomas ou princípios separados da natureza, o silogismo está longe de apreender as coisas reais. "O silogismo não é empregado para o descobrimento dos princípios das ciências; é baldada a sua aplicação a axiomas intermediários, pois se encontra muito distante das dificuldades da natureza. Assim é que envolve o nosso assentimento, não as coisas" (NO I, 13). Na ciência aristotélica, bem como em boa parte da ciência grega, a mente humana não tem vínculos com a natureza, ficando enredada em seu próprio discurso. Esse é, talvez, o principal defeito dessa concepção de ciência; a ciência baconiana visa, sobretudo, ligar a mente e o discurso humano à natureza e às coisas reais.

Além disso, o silogismo pressupõe também as noções gerais pelas quais classificamos a natureza e, longe de propor uma classificação rica, diversificada e sofisticada, o filósofo que emprega o silogismo passa rapidamente por essa difícil, necessária e meticulosa tarefa. "O silogismo consta de proposições, as proposições de palavras, as palavras são o signo das noções. Pelo que, se as próprias noções (que constituem a base dos fatos) são confusas e temerariamente 
abstraídas das coisas, nada que delas depende pode pretender solidez" (NO I, 14; cf. PC II, XIII, 4, p. 190/388). Também os termos que compõem as proposições, as quais servem de premissas, devem ser adequados à natureza. No entanto, o estudo da lógica não diz respeito a como esses termos devem ser alcançados, visto que a lógica trata apenas dos aspectos formais, abstraindo de todo conteúdo.

Bacon levanta, ainda, outro problema de recorrer somente ao silogismo. Se almejamos o progresso da ciência, o silogismo não pode ser um bom instrumento, já que ele não nos faz avançar no conhecimento. O silogismo, na verdade, não inventa nada, nem conduz a axiomas e princípios. A conclusão de um silogismo não traz nenhuma novidade em relação às premissas, mas somente explicita o que nelas está implícito ou, como diz Bacon, recorda o que já sabíamos. "A invenção de discursos e argumentos não é propriamente invenção, pois inventar é descobrir o que não se sabe, não recuperar ou invocar o sabido" (PC II, XIII, 6, p. 192/389). Assim, o recurso do silogismo não traz, para o nosso conhecimento, "nenhum acréscimo ou ampliação" (PC II, XIII, 6, p. 192/389).

Finalmente, segundo Bacon, o procedimento é estéril: não produz obras, está distanciado da prática e é incompetente para a parte ativa das ciências (Distributio, p. 78). Se o fim da ciência não é vencer o adversário, arrancando-lhe o assentimento por meio de um argumento supostamente decisivo, mas antes vencer a natureza numa atividade cooperativa, então o recurso à lógica não permite realizar o fim da ciência. É preciso auxiliar o intelecto de outra maneira para que se possa construir uma ciência segura e em contato com a natureza.

A ciência baconiana propõe uma via indutiva como o caminho mais adequado à produção do conhecimento científico. A via da dialética, apoiada no silogismo, conduz a um beco sem saída, como acabamos de ver. "Aqui está por que a única esperança radica na verdadeira indução" (NO I, 14). Logo abaixo, teremos a oportunidade de examinar com cuidado a natureza da demonstração indutiva. Portanto, a natureza da demonstração da nova ciência é a (verdadeira) indução, e não o silogismo.

Antes, porém, de nos dedicarmos à indução baconiana, cabe dizer algumas palavras sobre a ordem das demonstrações (cf. Distributio, p. 78). Segundo Bacon, "só há e só pode haver duas vias para a descoberta da verdade. Uma, que consiste no saltar-se das sensações e das coisas particulares aos axiomas mais gerais e, a seguir, descobrirem-se os axiomas intermediários a partir desses princí- 
pios e de sua inamovível verdade. Segundo Bacon, os antigos foram Esta é a que ora se segue. A ou- muito claros sobre seus proceditra, que recolhe os axiomas dos mentos (NO I, 125). Sua concepdados dos sentidos e particula- ção era basicamente dedutivista, res, ascendendo contínua e gradualmente até alcançar, em último lugar, os princípios de máxima generalidade. Este é o verdadeiro caminho, porém ainda não instaurado" (NO I, 19). Assim, a ciência aristotélica parte dos sentidos, alcança rapidamente os princípios gerais e as noções gerais e deduz, desses princípios, os axiomas intermediários.

Essa ordem, no entender de Bacon, deve ser modificada. Embora também parta dos sentidos, ${ }^{19}$ a ciência baconiana progressivamente inventa os axiomas intermediários para, finalmente, alcançar os princípios e as noções gerais. Percebese, portanto, que um dos principais problemas da via antiga é a abstração grosseira das noções gerais e a formulação precipitada de princípios gerais. Numa palavra, a indução é um procedimento indispensável, do qual nem mesmo os defensores do uso do silogismo podem livrar-se. No entanto, ao darem excessiva atenção às regras da dedução, acabaram por ignorar quase completamente a indução, que, então, conceberam de É preciso distinguir entre duas forforma extremamente simplificada. mas de indução: "Para constituir

\footnotetext{
${ }^{19}$ Veremos, a seguir, que mesmo o ponto de partida da ciência baconiana é profundamente diferente do ponto de partida da ciência grega.
} 
nossos axiomas, precisamos pensar uma forma de indução diferente da usada até aqui..." (NO I, 105).

Quais são as características da indução pressuposta por essa ciência legada pelos antigos? Embora simples, os dialéticos tinham uma concepção precisa da indução, que seria como uma espécie de enumeração a partir da qual se faz uma generalização (Distributio, p. 78). Várias passagens, de conteúdo semelhante, indicam essas características. Vejamos essas passagens: "Com efeito, a forma discutida pelos dialéticos procede por simples enumeração" (NO I, 17; cf. NO I, 105). Ora, Bacon atribui aos antigos a forma mais elementar de indução: uma simples generalização a partir dos casos observados. Assim, a indução levaria em conta somente os casos positivos de uma correlação observada entre eventos. Um exemplo seria: de alguns cisnes são brancos, infere-se que todos os cisnes são brancos. A função da indução por simples enumeração é fundamentar e descobrir os primeiros princípios (NO I, $19,105)$. Como vimos, não se poderia propor um silogismo, qualquer que fosse, sem dispor de noções gerais e de princípios universais. Assim, a indução deveria fornecer ao filósofo a matéria com a qual formularia seus silogismos e deduções.

Essa concepção da indução é, para Bacon, francamente insatisfatória: trata-se de "uma coisa pueril insegura em suas conclusões, vulnerável a um caso contraditório, ocupando-se somente do costumeiro e incapaz de obter resultados" (NO I, 17). Mais adiante, Bacon repete essas críticas. "Com efeito, a indução, procedendo por simples enumeração é um assunto pueril, suas conclusões não são seguras, está aberta à instância contraditória e geralmente baseia seu veredicto em menos fatos do que o necessário e, entre esses, somente aqueles que são mais acessíveis" (NO I, 105). A conclusão não é segura, pois a experiência certamente não sustenta a conclusão; está aberta à instância contraditória, porque basta encontrar um cisne não-branco para que se torne falsa; baseia sua conclusão em menos fatos do que o necessário, não porque seria preciso observar infinitos cisnes brancos para chegar a essa conclusão, mas porque se limita a um único tipo de correlação, sem ampliar a base indutiva; finalmente, limita-se aos fatos mais acessíveis, porque diz respeito somente a qualidades observáveis aos sentidos. "Pois concluir de uma enumeração de particulares sem instância contraditória não é conclusão, mas conjectura, porque quem pode assegurar (em muitas matérias), baseando-se naqueles particulares que aparecem de 
um lado, que não haja outros do lado contrário que não aparecem?" (PC II, XIII, 3, p. 189/387).

Esse procedimento indutivo é resultado de uma atitude natural da mente humana. Bacon afirma que a indução por simples enumeração é um dos quatro erros a que a mente humana está sujeita (NO I, 69). É, com efeito, um método falacioso antecipar o novo a partir do velho que já se conhece (NO I, 109). Ora, é precisamente isso que faz a indução por enumeração: ao observarem-se muitos cisnes brancos, espera-se que, no futuro, somente se encontrarão cisnes brancos. Como nota Bacon na doutrina dos Ídolos da Tribo, ${ }^{20}$ "o intelecto humano é propenso a supor que há mais ordem e igualdade nas coisas do que realmente existe" (NO I, 45). Essa indução precipitada, que rapidamente chega a princípios universais e primeiros, é mais fruto de um intelecto distanciado das coisas do que de um conhecimento objetivo de como as coisas são. Mas, uma vez que se formulou uma regra universal, a mente humana não quer abandoná-la. Embora seja fácil encontrar casos contrários, o filósofo que cede às inclinações naturais da mente humana não cederá às evidências e descartará o contra-exemplo. O intelecto humano tende a desconsiderar casos contrários, uma vez que já aceitou algo como correto (NO I, 46). Ora, ver mais ordem do que existe e rejeitar aquilo que nega a ordem imaginada pelo intelecto parece corresponder precisamente à indução por enumeração.

Assim, é preciso inventar a verdadeira indução, que seja diferente da indução por enumeração e cuja finalidade é fundamentar noções e primeiros princípios. Bacon proporá o que se convencionou chamar de indução eliminativa (por oposição à indução por enumeração). "Mas a Indução a ser empregada na descoberta e demonstração das ciências e artes deve separar uma natureza por adequadas rejeições e exclusões e, então, depois de considerar suficientes negativas, tirar conclusões das afirmativas, o que é uma coisa jamais feita até aqui" (NO I, 105). Nessa concepção baconiana da indução, há um progresso lento, que parte do experimento, passando pelos axiomas menos gerais, depois pelos intermediários, até que finalmente se possam alcançar as formas das naturezas simples das coi-

\footnotetext{
${ }^{20}$ A Teoria dos Ídolos, exposta no primeiro livro do Novum organum, aforismos 38-70, é uma das partes mais conhecidas da filosofia de Bacon. Aproxima-se, com frequência, essa doutrina da crítica cartesiana aos preconceitos contida na primeira de suas Meditações. Bacon identifica quatro fontes que estariam na base de nossos erros, impedindo o conhecimento. Os Ídolos da Tribo seriam um desses quatro tipos de erros a que todos estamos inevitavelmente sujeitos.
} 
sas. "Essa indução deve, além disso, ser usada não somente para descobrir os axiomas, mas também para fixar nossas noções" (NO I, 105).

Bacon concebeu três tábuas para que a indução possa ser adequada. A primeira é a de instâncias positivas, isto é, "sobre uma natureza dada deve-se em primeiro lugar fazer uma citação perante o intelecto de todas as instâncias conhecidas que concordam com uma natureza, mesmo que se encontrem em matérias dessemelhantes" (NO II, 11). A essa tábua, Bacon deu o nome de tábua de essência e de presença. Em seguida, "deve-se fazer uma citação perante o intelecto das instâncias privadas da natureza dada, uma vez que a forma, como já foi dito, deve estar ausente quando está ausente a natureza, bem como estar presente quando a natureza está presente" (NO II, 12). Essa tábua de ausência permite excluir da indução certas correlações que não ocorrem na natureza, mas que poderiam ser sugeridas pela primeira tábua. A terceira tábua é a de graus ou comparação e serve para confirmar a correlação encontrada em graus intermediários. "É necessário fazer-se citações perante o intelecto das instâncias cuja natureza, quando investigada, está presente em mais ou em menos, seja depois de ter feito a comparação do aumento e diminuição em um mesmo objeto, seja depois de ter feito uma comparação em objetos diversos" (NO II, 13).

A indução eliminativa, contudo, não termina enquanto não se fizer uma afirmação positiva. Após encontrar inúmeras correlações na tábua positiva, eliminar diversas falsas correlações e confirmar algumas na tábua de graus, resta ainda propor, após esse longo e exaustivo processo, a forma procurada. Todo esse processo de exclusão e eliminação não visa senão à descoberta da forma. Como foram excluídas todas as instâncias contrárias, como se examinou uma enorme diversidade de casos, procedendo a minuciosas investigações, avançando lentamente e ampliando ao máximo a base empírica, Bacon crê que a conclusão dessa indução não sofre dos defeitos da indução por enumeração: a afirmação sobre a forma seria, assim, segura e não estaria aberta a contra-exemplos. ${ }^{21}$

Chegamos, agora, ao terceiro ponto de divergência entre a concepção que os antigos tinham de ciência e a proposta baconiana de uma nova ciência. Qual deve ser o ponto de partida da ciência? Para Bacon, na ciência aristotélica, a dialética (ou lógica comum) toma emprestados os princípios das ci-

\footnotetext{
${ }^{21}$ Zagorin (1999), p. 99; Malherbe (1999), p. 91-2.
} 
ências particulares; haveria um experientia como o experimentum. grande respeito pelas noções pri- Nesse sentido amplo, a experiênmeiras da mente; e apoiar-se-ia nas cia é o ponto de partida de toda informações imediatas dos senti- e qualquer ciência e recebe, por dos. Mas a nova ciência a ser instaurada deve ter um ponto de partida diferente. Na ciência baconiana, a lógica deve impor-se às ciências particulares com autoridade superior aos princípios de cada uma das ciências particulares. Por um lado, não se deve confiar no entendimento, já que este não é como um espelho neutro e indiferente, mas está cheio de "idolos" que deformam as imagens das coisas, ou seja, de preconceitos e tendências nocivas ao conhecimento, de forma que é preciso reformá-lo para que possa produzir uma verdadeira ciência das coisas. Por outro lado, também não se deve confiar nas informações dos sentidos, visto que esses podem nos enganar. É preciso, pois, auxiliar os sentidos. Como veremos a seguir, o principal auxílio que se pode dar aos sentidos é o experimento.

\section{A ideia de experimento.}

Bacon traça uma distinção fundamental para que possamos entender o ponto de partida da ciência. De um lado, temos a experiência (experientia) e, de outro, o experimento (experimentum). Mas "experiência" pode ter um sentido maneiras. De um lado, os sentidos mais amplo, abrangendo tanto a distraem a mente, pois só pensa- 
mos em alguma coisa quando esta é perceptível e as coisas invisíveis não captam nossa atenção e, de outro, a percepção sensível simples não deve servir de ponto de partida para a ciência porque somente revela algumas poucas qualidades mais superficiais das coisas e não a sua realidade interna. Os sentidos apenas nos mostram as coisas na medida em que têm relação conosco, de forma que, se julgarmos com base na observação comum, nossa mente continuará divorciada do mundo, sem ser capaz de conhecer sua estrutura interna, e restrita ao que é meramente subjetivo.

A esse respeito, é indispensável retomar a teoria da matéria desenvolvida por Bacon. ${ }^{22}$ Haveria dois tipos de matéria, a mais grosseira e visível, que são os corpos ordinários, e a mais sutil e invisível, composta por partículas diminutas que escapam aos nossos sentidos. A experiência comum, portanto, somente nos oferece algumas virtudes ou características mais superficiais das coisas e não nos faz penetrar na sua natureza, nem avançar em direção às formas ou sequer aos axiomas intermediários, somente apresentando as coisas como estas aparecem para nós, e não a matéria em seu íntimo ou em suas partes internas, invisíveis e sutis. Como corrigir essas duas fragilidades dos sentidos? A ciência grega pouco ou nada avançou nessa direção.

Um auxílio seria fornecer instrumentos aos sentidos, como telescópios e microscópios. Esse recurso, embora amplie a capacidade dos sentidos e, por isso, seja muito útil, corrigindo a primeira fragilidade, é claramente insuficiente para corrigir a segunda fragilidade dos sentidos. Enquanto as informações sobre as coisas forem as informações sensíveis, sempre estaremos presos às qualidades aparentes das coisas ou ao mundo empírico, nunca nos aproximaremos da natureza das coisas ou de sua realidade interna, isto é, de suas formas ou de suas leis e operações causais. Por isso, conclui Bacon, "instrumentos para ampliar e aguçar os sentidos não valem muito" (Distributio, p. 79-80). Afinal, mais importante é penetrar na natureza das coisas do que somente observar mais qualidades aparentes, como a de corpos distantes ou muito pequenos. Os sentidos, então, precisam de um auxílio mais poderoso que meros instrumentos, como as lentes.

O segundo e mais eficaz auxílio aos sentidos são "experimentos aptos e adequados", uma vez que estes nos permitem avançar em direção ao conhecimento dos processos invisíveis e da natureza

\footnotetext{
${ }^{22}$ Para a relação de Bacon com o atomismo, ver Manzo (2006, 2008) e Zaterka (2012).
} 
das coisas. Os experimentos permitem obter informações que os sentidos, mesmo ajudado por lentes, não obteriam. Os instrumentos apenas melhoram um pouco a qualidade da informação fornecida pelos sentidos e ampliam as coisas percebidas, mas, de resto, são pouco úteis, fornecendo somente informações sobre suas aparências. Experimentos, ao atormentar a natureza para que esta se manifeste e responda às nossas perguntas, permitem obter informações objetivas sobre as coisas. Numa frase lapidar, Bacon enuncia o papel que os experimentos devem desempenhar na construção do saber: "os sentidos julgam somente o experimento, enquanto o experimento julga a coisa" (NO I, 50; cf. NO, Plano da obra, p. 35).

Naturalmente, os dois auxílios podem ser empregados concomitantemente na tentativa de responder a uma pergunta científica. Bacon, para examinar se há calor nos raios da Lua (NO II, 36), concebe um estratagema que envolve os dois auxílios acima mencionados: o recurso a um instrumento para ampliar os sentidos e, sobretudo, um experimento que permita extrair uma informação que, não fosse o curso comum da natureza alterado, jamais a obteríamos. A questão é descobrir to- das as coisas que têm calor. Sabemos, pelos sentidos, que os raios solares são quentes. O que dizer dos raios lunares? Os sentidos não indicam que há neles calor. Mas não se podem julgar as coisas pelo modo como as percebemos pelos sentidos. É preciso, portanto, bolar um experimento que nos permita averiguar se os raios lunares têm ou não calor. Assim como a convergência dos raios solares aumenta seu calor e permite até queimar uma folha seca, é possível fazer convergir os raios lunares, por meio de uma lente, de modo a ampliar seu calor e, assim, constatarmos se têm ou não calor. ${ }^{23}$

É certo que a ciência grega recorreu, às vezes, ao experimento. No entanto, o recurso ao experimento era ocasional, nunca sistemático. Assim, na ciência grega, pode-se falar, além da observação, de um experimento casual, mas nunca de uma reflexão e sistematização em que o experimento constitui uma parte essencial. "Resta a mera experiência, que é chamada acidente, se acontece por si mesma, mas experimento, se é deliberadamente buscada" (NO I, 82). Assim, outra diferença crucial entre a mera experiência e o experimento é que a primeira é casual, ao passo que o segundo é deliberado. Também dentro dos experimentos, deve-se

\footnotetext{
${ }^{23}$ Há um conjunto de "instâncias” que visam ao auxílio dos sentidos: as instâncias da lâmpada (XVI-XX: 38-42).
} 
distinguir entre um experimento acidental, como o dos alquimistas ou de William Gilbert, e um experimento intencional, como o que Bacon propõe. O primeiro ocorre como que por acaso, de maneira isolada, sem levar a outros experimentos, nem a teorias causais explicativas. No melhor dos casos, há apenas uma variação de experimentos já conhecidos, uma vez que a indução por enumeração pede a repetição ou a mera variação do experimento. Os experimentos de que a nova ciência necessita são efetivamente protocolos, ou seja, experimentos gerados numa certa ordem e regra, de acordo com o que indagamos. ${ }^{24}$ Não basta que os experimentos sejam deliberados, mas é preciso que sejam frutos de um método e articulados num sistema de investigação da natureza mais amplo (cf. NO I, 73).

A respeito da noção de experimentum em Bacon, é crucial notar a dependência do experimento em relação às teorias. ${ }^{25}$ Conforme a ciência progride, os experimentos dependerão cada vez mais dos axiomas intermediários propostos. Não se deve, contudo, pensar a constituição da ciência de modo contínuo e ascendente, como se partíssemos de uma coleta ampla e diversificada de informações sobre as coisas e, depois, usando as tábuas de presença, ausência e comparação, começássemos a induzir os axiomas em direção às formas sem jamais voltar às informações empíricas. Há, certamente, muitas passagens que sugerem essa interpretação da constituição da ciência baconiana: "uma ordem adequadamente estabelecida leva por uma estrada direta por meio da floresta da experiência para o campo aberto dos axiomas" (NO I, 82). Outra passagem parece confirmar essa ideia de um progresso lento, mas contínuo, da experiência para as formas: "Devemos esperar coisas melhores das ciências somente quando subirmos a escada adequada por passos sucessivos, ininterruptos ou não-quebrados, de axiomas particulares para axiomas menores, então a intermediários, cada vez mais altos do que o último até que finalmente chegamos ao mais geral" (NO I, 104). Essas passagens atestam somente a ideia de um progresso científico, não a

\footnotetext{
${ }^{24}$ Bacon enfatizou muito mais o papel do experimento na nova ciência do que o papel que as matemáticas nela desempenharam. No entanto, Bacon admitiu a "matemática mista", isto é, a que "tem por objeto certos axiomas ou partes da filosofia natural e considera a Quantidade determinada auxiliar e incidente a eles, pois muitas partes da natureza não podem ser desveladas com sutiliza suficiente, nem expostas com clareza suficiente, nem acomodadas ao uso com facilidade, se não for com o auxílio e intervenção da matemática" (PC II, VIII, 2, p. 155/360). Embora ainda visse um uso restrito da matemática mista a algumas ciências, Bacon reconheceu que "quanto à matemática mista, só posso fazer esta previsão, que forçosamente existirão mais tipos dela à medida que a natureza for sendo mais desvelada" (PC II, VIII, 2, p. 155/360). Eis uma previsão certeira!

${ }^{25}$ Garber (2001) sustenta, com razão, que a experiência e o experimento, em Bacon, são carregados de teoria.
} 
de que, nesse progresso, os experimentos são deixados para trás e constituem somente a base inicial para a formulação de teorias.

A relação entre experiência (como experimento) e axioma (ou teoria) é certamente mais complexa do que parece. ${ }^{26}$ Para percebermos essa complexidade, cabe relembrar a famosa ideia de Bacon segundo a qual devemos interrogar a natureza e, por meio de "tormentos", extorquir-lhe respostas. Não se pode exagerar a importância dessa ideia, já que "na faculdade de saber interrogar está metade do conhecimento" (PC II, XIII, 9, p. 194/391). Entender como experimentos são inventados a partir de uma certa preocupação teórica é entender como, para Bacon, interrogamos a natureza. Vejamos isso mais de perto.

Numa passagem que reconhece que uma teoria pode impedir um experimento ou atrapalhá-lo, Bacon também diz que uma teoria pode promovê-lo. "O trabalho árduo dos químicos produziu alguma coisa, mas como que por acidente e fortuitamente, ou por alguma variação de seus experimentos e não por alguma arte ou teoria; pois a teoria que eles produziram mais atrapalha os experimentos do que os promove" (NO I, 73).
Assim, a direção não é unívoca: do experimento para os axiomas, mas também pode se dar o contrário: dado um axioma, podemos conceber um novo experimento. Essa ideia já havia sido aventada anteriormente. "Toda filosofia natural verdadeira e frutífera tem uma escala ou escada dupla, ascendente e descendente, ascendendo dos experimentos à invenção das causas, e descendendo das causas à invenção de novos experimentos" (PC II, VII, 1, p. 143/351-2).

Bacon pensava que os axiomas propostos geravam novos experimentos, os quais jamais seriam concebidos sem esses axiomas. Após referir-se ao tipo de experiência, que é acidental, diz Bacon: "A verdadeira ordem da experiência é outra: primeiro, acende uma luz e, então, usa-a para encontrar o caminho, começando com a experiência ordenada e digerida, e não desordenada e confusa, e, daí, inferindo axiomas e, de axiomas estabelecidos, operando de novo para baixo em direção a novos experimentos" (NO I, 82). Ora, essa passagem deixa bastante claro que a experiência é "ordenada e digerida", não casual; mais do que isso, quando a experiência é ordenada e digerida, permitindo a inferência de axiomas, então novos expe-

\footnotetext{
${ }^{26}$ Essa é a interpretação, por exemplo, de Gaukroger (2001), p. 145-6. Ver também Martin (1995), p. 84-5, Zagorin (1999), p. 98-103, e Malherbe e Pousser (2004), p. 43-5.
} 
rimentos são realizados, de forma que não há somente uma linha ascendente, que parte da experiência em direção às formas, passando pelos axiomas intermediários, mas que, uma vez alcançados alguns axiomas, novos experimentos são realizados, isto é, força-se a natureza a revelar novos aspectos antes desconhecidos por meio de uma violência ao seu curso comum e espontâneo. Assim, a cada nível superior de abstração correspondem novos experimentos para que se possa prosseguir na busca das formas.

De fato, Bacon reconhece que haveria como que uma rua de mão dupla entre as coisas particulares e os axiomas: "devemos esperar muito menos disso [experiência letrada] do que da nova luz dos axiomas inferidos de particulares por uma rota e fórmula fixa, axiomas que por sua vez apontarão e especificarão novos particulares, pois essa rota não está traçada no plano, mas sobe e desce - subindo primeiro até os axiomas e, então, descendo para as obras" (NO I 103). Embora fale somente de "obras", é certo que, para Bacon, resultar em obras é uma confirmação dos axiomas propostos. Parte importante desse movimento de subir e descer é que uma primeira indução deve ser ampliada para novos casos, ampliando a base empírica, e não permanecer restrita aos casos observa- dos de que foi induzida. Assim, um axioma deve ser fértil e iluminar casos imprevistos; em seguida, esse axioma deve ser testado. "Ao formarmos axiomas por essa forma de indução, devemos testar e ver se o axioma assim formado é apropriado e feito à medida dos particulares de que é derivado ou se é mais amplo e extenso. Ora, se é mais amplo e extenso, devemos ver se essa amplidão e extensão são confirmadas, como por uma espécie de garantia, pela especificação de novos particulares" (NO I, 106).

Bacon deixa claro que sua rota e plano "não me levam a extrair obras de obras, ou experimentos de experimentos (como fazem os empiristas), mas extrair (como fazem os legítimos intérpretes da natureza) de obras e experimentos causas e axiomas, e, por sua vez, de causas e axiomas novas obras e experimentos" (NO I, 117). Ora, novos experimentos são, segundo sua rota, resultado de causas e axiomas. Na verdade, um experimento pode conduzir a outros experimentos, mesmo sem a passagem pelas causas e axiomas. "E, em segundo lugar, que não apenas sejam validados os experimentos que tenham uma utilidade imediata e presente, mas principalmente os que encerram consequências mais amplas para a invenção de outros experimentos" (PC II, VIII, 4, p. 158/363). Portanto, o método in- 
dutivo de Bacon não é sempre somente ascendente, mas, para continuar subindo, é preciso constantemente voltar ao nível da experiência e realizar novos experimentos, para continuar a formular axiomas de graus cada vez mais altos de abstração. ${ }^{27}$

Bacon empregou metáforas, que se tornaram famosas, para caracterizar a posição empirista, a dogmática e a sua própria posição. Os empiristas, como formigas, recolhem experimentos e os usam; os dogmáticos ou racionalistas, como aranhas, tecem teias a partir de sua própria barriga; mas as abelhas seguem um caminho intermediário: coletando material das flores, produzem o mel. Os experimentos, nesta última concepção, a de Bacon, devem ser modificados e elaborados pelo intelecto. Poderse-ia ver, nessa metáfora, a ideia de que a elaboração da teoria seria uma segunda etapa, posterior ao experimento. Mas essa parece ser uma leitura equivocada da metáfora, pois não há exterioridade entre experimento e intelecto, já que Bacon se refere a "uma aliança mais estreita e pura (ainda não realizada) dessas duas faculdades (a experimental e a racional)" (NO I, 95). Assim, talvez se possa ver, na famosa metáfora da abelha de Bacon, não somente a continuidade dos experimentos e da teoria, mas também uma interação constante entre experimento e teoria. ${ }^{28}$

Finalmente, Bacon fecha seu livro I do Novum Organum ressaltando precisamente o caráter dinâmico, por assim dizer, de sua proposta. ${ }^{29}$ Bacon tem plena consciência de que sua instauração da ciência depende de muitos homens, de muito dinheiro e de muito tempo. Ele não tem nenhuma teoria pronta a propor. Mas mesmo a verdadeira indução, que deve nos levar a essas teorias sobre a natureza das coisas, pode ser reformulada ao longo da instauração das ciências: "é minha convicção que a arte da descoberta crescerá conforme o numero de coisas descobertas crescer" (NO I, 130). Assim, a própria via proposta por Bacon para a nova ciência poderá ser corrigida e melhorada com o progresso da ciência. O método cien-

\footnotetext{
${ }^{27}$ Zagorin (1999, p. 102): “A indução eliminativa descrita no Novum Organum envolvia a interrogação contínua da natureza e a busca de respostas às questões colocadas. Em cada etapa, o filósofo natural está consciente do que quer saber e tenta inventar maneiras de obter esse conhecimento. A investigação nunca é não-dirigida. As questões colocadas para a natureza levantam questões adicionais. Algumas das questões são como hipóteses que sugerem experimentos, que são a razão para muitos experimentos que Bacon propôs em seu tratado. Algumas das respostas se tornam axiomas. Esses, por sua vez, agem como teorias que apontam para outras linhas de investigação e também levam a experimentos".

${ }^{28}$ Porque Bacon critica simultaneamente empiristas e racionalistas e incorpora elementos de ambas as vertentes numa proposta original, é difícil, se não impossível classificá-lo seja como empirista, seja como racionalista.

${ }^{29}$ Cf. Malherbe e Pousseur (2004), p. 44.
} 
tífico não é fixo, mas progride conforme a própria ciência progride.

Ora, essa interação entre a parte experimental e a parte teórica da ciência não se faz sem a mediação da história natural e terá implicações importantes para a própria concepção de como esta última deve ser constituída. Veremos, a seguir, que a ideia de ciência levará à proposta de uma nova concepção de história natural. Sem a referência à instauração de uma nova ciência, não haveria por que articular um novo conceito de história natural. Uma questão chave para a elaboração dessa concepção de história natural é: como a experiência e o experimento poderão ser transformados em matéria ou assunto para a ciência?

\section{A ideia de história}

Assim como a concepção de ciência nos levou a considerar a concepção de experiência como experimento, porque todo conhecimento parte da experiência (a verdadeira indução exige uma concepção diferente da experiência como experimento deliberado e metódico, e não como observação casual ou errática), assim também a concepção de experiência deve nos levar à de história, porque o fundamento da experiência não foi suficientemente pensado pelos filósofos. "Agora, os fundamentos da experiência (uma vez que se deve, em qualquer caso, chegar a isso) ou são inexistentes ou extremamente fracos, nem alguém até agora pensou e colheu uma floresta de particulares e materiais do número, tipo ou confiabilidade de alguma maneira suficiente para informar o intelecto" (NO I, 98). Assim, pensar a história, em particular a história natural, é pensar os fundamentos da experiência, é pensar como a experiência pode servir de matéria para o intelecto e, portanto, construir uma história experimental da natureza. Cabe, agora, mostrar como a nova ciência de Bacon se faz acompanhar de uma nova ideia de história natural.

Não há dúvidas de que Bacon propõe o que, a seus olhos, seria uma nova história. "Mas nossa história (como nossa lógica) difere da atual de várias maneiras: em seu fim ou função, em sua própria grandeza (mass), em sua sutileza e também na sua seleção e organização para os procedimentos que vêm depois dela." (NO, Plano da obra, p. 39-41) Quatro diferenças, portanto, separam a história natural de Bacon de outras histórias naturais: finalidade, grandeza, sutileza e seleção. Examinemos cada uma delas separadamente. ${ }^{30}$

\footnotetext{
${ }^{30}$ Para uma avaliação geral dos diversos tipos de história, ver PC II, I-III, p. 112-31/329-42.
} 
Primeira, a finalidade ou função com que se escreve uma história, que deixa de ser vista como uma coleção de fatos e passa a ser a matéria prima para o intelecto por ser uma investigação exaustiva de todos os dados empíricos que possam ser observados e coletados. As histórias naturais têm comumente por finalidade agradar ao exibir a variedade das coisas. Assim, essas histórias apresentam novidades para satisfazer a curiosidade. A razão de ser das histórias naturais comuns encerra-se em si mesma (NO I, 98). Além disso, essa história natural não colhe frutos maduros, mas apressa-se em relatar as novidades. A história natural de $\mathrm{Ba}-$ con, ao contrário, tem por finalidade fornecer informações para o intelecto. Por isso, deverá esperar o amadurecimento das experiências, já que não é qualquer experiência que deverá ser relatada. É preciso que, na época certa da colheita, os frutos sejam adequadamente descritos, caso contrário, não cumprirá com sua função ou finalidade. $\mathrm{O}$ intelecto deve ser informado apenas daquilo que é seguro.

A segunda diferença diz respeito à sua grandeza, pois a história natural de Bacon pretende ser maior do que as histórias naturais de dois pontos de vista. De um lado, por incluir, ao lado das observações do curso natural dos acontecimentos naturais, relatos de experimentos que forçam a natureza a manifestar-se numa ou noutra direção. De outro lado, por uma diversidade de assuntos que normalmente são ignorados. Vejamos, com mais cuidado, cada um desses pontos de vista.

As histórias naturais costumam relatar somente os acontecimentos espontâneos, isto é, aqueles que ocorrem naturalmente, sem a intervenção do homem. São histórias de uma "natureza livre e nãoconstrangida", isto é, "quando a natureza segue seu próprio caminho e faz seu trabalho". Bacon inclui, em sua história natural, outro tipo de acontecimentos: aqueles que são extraídos à força da natureza, quando esta é "espremida e moldada". Portanto, na história natural devem entrar os experimentos, como os das artes mecânicas. Essa parte da história natural, que relata experimentos que torturam a natureza, é ainda mais importante do que a que relata acontecimentos espontâneos. Como vimos, a mera observação não penetra nos segredos da natureza, mas somente nos fornece as aparências externas, enquanto os experimentos revelam

\footnotetext{
${ }^{31}$ Zagorin (1999, p. 104) distingue três estados ou manifestações da natureza: livre, fora do curso ordinário, manipulada pelo homem.
} 
melhor o interior da natureza. ${ }^{31}$

Além disso, as histórias naturais costumam ser somente histórias de corpos, mas Bacon pensa que é preciso ampliar e diversificar as histórias naturais, incluindo, por exemplo, as histórias das "virtudes" que são cardinais para a natureza, como denso, raro, quente, frio, consistente, fluido, pesado e leve. Não se trata de somente enriquecer um mesmo tipo de história natural, como se faltassem alguns tópicos nas histórias naturais comuns. Bacon entende que cada uma dessas "virtudes" merece uma história natural à parte, isto é, que é preciso dedicar uma história natural para cada uma. Assim, é a própria concepção de história natural do corpo que é substituída por uma multiplicidade de histórias naturais muito mais ricas e com foco diversificado.

A sutileza constitui a terceira diferença. Bacon entende que os experimentos que sua história natural deve relatar são muito diferentes dos experimentos relatados pela história natural usual. Nesta, lê-se somente aquilo que se encontrou ao acaso, portanto algo que não se procurava sistematicamente. Ora, a história natural baconiana relata experimentos que são deliberadamente buscados. "E esses dois tipos de história diferem em muitos aspectos, mas acima de tudo nesse: que a primeira admite a variedade de espécies naturais, mas não os experimentos das artes mecânicas" (NO I, 98). Assim, pode-se constatar algo que, não fosse essa intenção de investigar uma causa específica, jamais seria encontrado. Como essas coisas que se buscam deliberadamente não são úteis em si, nem óbvias, elas passam despercebidas. Por isso, jamais serão relatadas numa história natural escrita nos moldes usuais. Mas, numa história natural que incorpora experimentos deliberados, força-se a natureza a manifestar-se de maneira pouco usual, revelando outros efeitos e permitindo avançar no descobrimento das causas. "Os segredos da natureza traem-se a si mesmos mais por meio dos tormentos da arte do que faz em seu curso usual" (NO I, 98). Assim, por incluir experimentos pensados e planejados, a história natural baconiana será muito mais sutil, isto é, revelará aspectos da natureza que, de outro modo, seriam ignorados. Nem todos os experimentos, contudo, serão relatados. Com efeito, os experimentos frutíferos não têm a finalidade de indicar as causas dos processos naturais; esta é a finalidade dos experimentos luminosos. Portanto, somente estes últimos serão incluídos numa história natural, cuja finalidade é informar o intelecto (NO I, 121).

A quarta e última diferença está 
relacionada com a seleção e organização dos relatos para os procedimentos posteriores. Não é qualquer relato que deve ser incluído numa história natural com finalidade científica. Relatar um experimento com essa finalidade exige uma atitude crítica. Numa história natural que visa a agradar, qualquer relato de algo milagroso, fabuloso ou fruto de uma superstição pode ser incluído. Mas esses relatos causam mais danos à mente do que a ajudam a entender a natureza. Se a história natural é a primeira etapa da nova ciência, não se pode enchê-la com superstições e relatos crédulos. É preciso, portanto, selecionar o material que integrará a história na- tural. Bacon aceita não somente o que ele mesmo viu, mas também os testemunhos de pares confiáveis ou, pelo menos, testemunhos não confiáveis, mas que foram examinados severamente, sem nenhuma intenção de acentuar o caráter milagroso. No primeiro caso, é preciso incluir, no relato, como o experimento foi realizado, de modo que todos possam examinar por si mesmos se há erros, se as provas são confiáveis e exatas. No segundo caso (mas também no primeiro), é preciso incluir observações críticas sobre o que se relata, de modo que os experimentos possam ser úteis para a filosofia e para o trabalho do entendimento. ${ }^{32}$

\section{Referências bibliográficas}

BACON, Francis. (Distributio) "Distribution de l'oeuvre" in Bacon, F. (NO).

BACON, Francis. (NA) Nova Atlântida e A grande instauração, tradução, introdução e notas de Miguel Morgado, Lisboa: Edições 70, 2008.

BACON, Francis. (NO) Novum Organum, tradução e notas de Malherbe, M. e Pousser, J.-M., Paris: PUF, 2004. (Tradução brasileira: Ed. Abril, col. Os Pensadores, 2a . Edição, 1979, tradução: José Aluysio Reis de Andrade).

BACON, Francis. (PC) Da proficiência e o avanço do conhecimento divino e humano, São Paulo: Madras, 2006, tradução: Júlia Vidili (a segunda referência para página é da edição dessa obra de Bacon feita por Spedding, Ellis e Heath, Works, London: Longman, 1870).

\footnotetext{
${ }^{32}$ Instâncias que auxiliam a memória: (VI a X) (27-31): auxilio à memória e história natural.
} 
BACON, Francis. (GR) A grande restauração: Textos introduto' rios e A escada do entendimento, organização, tradução e notas de Alessandro Rolim de Moura e Luiz A. A. Eva, Curitiba: Segesta, 2015.

BACON, Francis. Works IV, ed. James Spedding, Robet Leslie Ellis, and Douglas Heath, London: Longman, 1870.

EVA, Luiz A. A. (2008) "Francis Bacon: ceticismo e doutrina dos ídolos" in Cadernos de História e Filosofia da Ciência, Campinas, 18/1: 4784.

EVA, Luiz A. A. (2011) "Bacon's 'Doctrine of the Idols' and skepticism" in Machuca, D. (ed.) Pyrrhonism in Ancient, Modern, and Contemporary Philosophy, Dordrecht: Springer.

GARBER, Daniel. (2001) "Experiment, Community, and the Constitution of Nature in the Seventeenth Century" in Descartes Embodied. Cambridge: Cambridge University Press.

GAUKROGER, Stephen. (2001) Francis Bacon and the Transformation of Early-Modern Philosophy, Cambridge: Cambridge University Press. MALHERBE, Michel. (1999) "Bacon's method of science" in Peltonen (1999).

MALHERBE, Michel. e Pousser, J.-M. (2004) "Introduction" in Bacon $(\mathrm{NO})$.

MANZO, Silvia. (2006) Entre el atomismo y la alquimia: La teoría de la material de Francis Bacon, Buenos Aires: Biblos.

MANZO, Silvia. (2008) "Francis Bacon y el atomismo: una nueva evaluación", Scientiae Studia, 6/4: 461-495.

MANZO, Silvia. (2015) "Uma nova ciência para um novo mundo. O projeto da grande restauração por meio de suas imagens", in Sképsis 12: 121-145.

MANZO, Silvia. (2017) "Reading Scepticism Historically. Scepticism, Acatalepsia and the Fall of Adam in Francis Bacon" in Charles, Sébastien; Smith, Plínio J. (eds.) Academic Scepticism in the Development of Early Modern Philosophy, Dordrecht: Springer.

MARTIN, Julian. (1995) "Francis Bacon, Authority, and the Moderns" in Sorell, T. (ed.) The Rise of Modern Philosophy: The Tension between the New and Traditional Philosophies from Machiavelli to Leibniz, Oxford: Clarendon.

MORGADO, Miguel. (2008) "Introdução" in Bacon, F. (NA).

OLIVEIRA, Bernardo J. (2010) Francis Bacon e a fundamentação da ciência como tecnologia, Belo Horizonte: Editora UFMG.

PELTONEN, Markku. (ed.) (1999) The Cambridge Companion to Bacon, 
Cambridge: Cambridge University Press.

PÉREZ-RAMOS, Antonio. (1999) “Bacon's forms and the maker's knowledge tradition" em Peltonen (1999).

ROSSI, Paolo. (2006) Francis Bacon: Da magia à ciência. Curitiba: UFPR. SMITH, Plínio J. (2012) "Por que Bacon pensa que o ataque cético ao dogmatismo é insuficiente?", Revista Latinoamericana de Filosofia 38: 31-63 (republicado em: Smith, Plínio J. O método cético de oposição na filosofia moderna, São Paulo: Alameda Editorial, 2016).

ZAGORIN, Perez. (1999) Francis Bacon, Princeton: Princeton University Press.

ZATERKA, Luciana. (2004) A filosofia experimental na Inglaterra do século XVII: Francis Bacon e Robert Boyle, São Paulo: FAPESP/Humanitas.

ZATERKA, Luciana. (2012) "A teoria da matéria de Francis Bacon e Robert Boyle: forma, textura e atividade", Scientiae Studia, 10/4: 681-709. 